\title{
The Effects of University Environment Factors on Faculty Members' Teaching Efficacy in Vietnam
}

\author{
Minh-Quang Duong (Corresponding author) \\ University of Social Sciences and Humanities, \\ Vietnam National University of Ho Chi Minh City \\ 10-12 Dinh Tien Hoang Street, District 1, Ho Chi Minh City, Vietnam \\ E-mail: duongminhquang@hcmussh.edu.vn
}

Received: August 22, 2017 Accepted: September 16, 2017 Published: September 20, 2017

doi:10.5296/ire.v5i2.11738 URL: http://dx.doi.org/10.5296/ire.v5i2.11738

\begin{abstract}
Teaching efficacy is a belief that instructors have in their own capacities to influence student engagement and learning. Most of the research conducted on teaching efficacy has focused on the elementary and secondary school teachers, even less is known about university faculty teaching efficacy in the countries like Vietnam. The purpose of this study was to investigate university faculty's perceptions of teaching efficacy in Vietnam and the relationship of perceived university environment factors to faculty' teaching efficacy was examined. A questionnaire measuring 27 items of six factors of teaching efficacy was distributed to 124 university faculty members in Vietnam. The results showed that the most faculty members were highly measured with their teaching efficacy and faculty members felt efficacious from the greatest to the least in the following dimensions: course design, class management, learning assessment, instructional strategy, technology usage, and interpersonal relation. In addition, university environment factors such as learning resources and organizational culture had significantly effects on faculty teaching efficacy. The study's implications for university management were also discussed.
\end{abstract}

Keywords: Teaching efficacy, university environment, Vietnamese higher education, faculty member

\section{Introduction}

Teaching efficacy is "a judgment about capabilities to influence student engagement and learning, even among those students who may be difficult or unmotivated (Woolfolk Hoy, 2004, p.1). According to Tschannen-Moran, Woolfolk Hoy and Hoy (1998, p. 232), teaching efficacy is considered as "teacher's belief in his or her capability to organize and execute 
courses of action required to successfully accomplish a specific teaching task in a particular context".

Teaching efficacy was developed in Bandura's (1997) social cognitive and self-efficacy theories which were four sources of efficacy expectation such as: mastery experience, verbal persuasion, vicarious experiences and physiological arousal. Bandura (1986, p.31) defined self-efficacy as "people's judgment of their capabilities to organize and execute courses of action required to attain designated types of performances". The research of Bandura showed that self-efficacy is a key concept of social cognitive theory which was that behavior is best understood in terms of a triadic reciprocal system - consists of three items: cognition, environment, and behavior. Cook (1998, p.14) identified that "teaching efficacy is not only an observable behavior, but also rather an individual belief".

The selection of positive teaching behaviors, efficacious teachers tend to have high student achievement. Ross (1994) suggested teachers with high sense of efficacy tend to be more use: 1) new approaches, 2) management techniques, 3) help students who had low academic achievement, 4) develop students' academic skills, 5) set attainable goals, and 6) persist in the face of student failure. Similarly, Woolfolk Hoy (2004) showed that teachers with a strong sense of efficacy spend more time teaching in areas, and are more open to new ideas, more willing to experiment with new methods, more committed to teaching, and tend to exhibit greater levels of planning, organization, and enthusiasm (Allinder, 1994). Overall, teacher efficacy tends to engage in more productive, quality teacher behaviors (Ashton \& Webb, 1986; Gibson \& Dembo, 1984).

Several studies showed that there were related factors influencing faculty teaching efficacy. Studies have shown that teaching efficacy affected student achievement (Esterly, 2003; Henson, 2001), student success (Tournaki \& Podell, 2005; Woolfolk-Hoy \& Davis, 2006), student learning motivation (Nolen, Ward, Horn, Campbell, Mahna \& Childers, 2007), and student effectiveness (Tschannen-Moran \& Woolfok-Hoy, 2001; Usher \& Pajares, 2006). Research of Goddard, Hoy and Woolfolk Hoy (2000) demonstrated that faculty teaching efficacy is related to students' academic achievement, intrinsic motivation, and learning efficacy. Tschannen-Moran, Woolfolk Hoy and Hoy (1998) identified that teacher efficacy has been connected with student attitudes, teachers' classroom behaviors, teachers' attitudes, teacher stress and burnout, and teachers' willingness to implement innovation. Furthermore, Research shows that teaching efficacy related to different psychological factors of the instructor, such as willingness to accept new ideas (Brouwers \& Tomic, 2003; Henson, 2001, Ross \& Bruce, 2007), persistence for student dissatisfaction (Gibson \& Dembo, 1984), spend time for teaching per semester (Kim, 2009), and teacher assessment (Gkolia \& Belias, \& Koustelios, 2014; Carara, Barbaranelli, Steca, \& Malone, 2006), classroom management behavior (Giallo \& Little, 2003; Henson, 2001), responsibility for student learning (Darling-Hammond, Chung, \& Frelow, 2002), trust and openness (Goddard, Hoy, \& Woolfolk-Hoy, 2004), and happiness of teacher (Mehdinezhad, 2012). However, there is as yet no empirical research on the relationship between faculty teaching efficacy and university environment factors (e.g, teaching resources and organizational culture). 
Almost studies have focused on the teachers' teaching efficacy in the elementary and secondary schools (Lin \& Gorrell, 2001; Tschannen-Moran \& Woolfolk Hoy, 2002) and little is known about the faculty teaching efficacy in higher education (Cook, 1998). However, there are some studies on effective teaching in higher education to focus on teaching conceptions. The research of Brown (1993) measured faculty teaching efficacy in five factors, including course design, use of media, class management, teacher-student interaction, assessment and feedback to students. Gow and Kember (1993) found nine subscales of teaching conceptions, such as: training for specific jobs, imparting information, knowledge of subjects, problem solving, motivator of students, use of media, facilitative teaching, pastoral interest, and interactive teaching. According to Mehdinezhad (2012), faculty members' self-ratings of their teaching efficacy clustered around six teaching self-efficacy factors: subject matters or content knowledge, curriculum and instruction knowledge, interaction or communication competencies, evaluation of learning or assessment, knowledge of the learning environment and implementing technology in the curriculum. In this study, we used 27 items of six factors of teaching efficacy by research of Chang, McKeachie, and Lin (2010). They included course design, instructional strategy, technology usage, class management, interpersonal interaction, and learning assessment. The faculty teaching efficacy in this study is defined by Chang et al. (2010), Tschannen-Moran \& Woolfolk Hoy (2001) as the faculty members' judgment of their capabilities in course design, instructional strategy, technology usage, classroom management, interpersonal relation, and learning assessment.

It is clear that very few studies have been conducted in the area of teaching efficacy in Vietnamese higher education sector. The findings of this study, therefore, contribute to fill in the literature gap of faculty teaching efficacy in higher education. It identifies and discusses factors in Vietnamese university faculty's teaching efficacy which contribute most to their teaching performance and students' learning achievement. The present study focuses on the following research questions: 1) What is the general level of faculty teaching efficacy in Vietnam? and 2) How is faculty teaching efficacy affected by university environment factors?

\section{Methodology}

\subsection{Sample}

Questionnaire was distributed to 140 faculty members who were drawn from faculty members to working full-time in the University of Social Sciences and Humanities (USSH) - one of six member universities of Vietnam National University of Ho Chi Minh City (VNU-HCM) and 124 questionnaires were returned for $88.6 \%$ return rate which exceeded the $30 \%$ response rate to most researchers for analysis purpose (Dillman, 2000; Malaney, 2002). All data of respondents were self-reported information which was prevalently used in higher education research (Gonyea, 2005). The study was chosen 5 of 124 faculty members in the USSH-VNUHCM to answer open-ended questions which done using a face to face interview.

Broken down by gender, the sample of this study included $39.5 \%$ males and $60.5 \%$ females. For marital status, $50.8 \%$ of respondents were single, and $49.2 \%$ were married. Faculty belongs to different age groups, respondent age distribution was $44.4 \%$ below 30 years old, $22.6 \%$ from 31 to 35 years old and $16.1 \%$ from 36 to 40 years old. For length of employment in faculties' 
current position, $41.9 \%$ had from 1 to 5 years and $25.8 \%$ had from 5 to 10 years. Almost of $79 \%$ whose highest degree attained from Asian countries and 13.7\% were Europe countries.

\subsection{Variables}

Faculty teaching efficacy identified as the dependent variable in this study. As showed in Table 1, faculty teaching efficacy was composed of 27 items which were clustered around six factors such as course design, technology usage, instructional strategy, classroom management, interpersonal relation, and learning assessment. For each item, the respondents were asked to rate academic members' level of teaching efficacy on a five-point Likert's scale ranging from 1 = "strongly disagree" to 5 = "strongly agree".

Table 1 . The construct validities and reliabilities of the faculty teaching efficacy questionnaire

\begin{tabular}{|c|c|c|c|c|}
\hline Factors & Items & $\begin{array}{l}\text { Factor } \\
\text { loadings }\end{array}$ & $\begin{array}{c}\text { Variance } \\
\text { explained } \\
(\%)\end{array}$ & $\begin{array}{c}\text { Cronbach's } \\
\boldsymbol{\alpha}\end{array}$ \\
\hline \multirow{5}{*}{ Course design } & Have sufficient professional ability & 0.847 & \multirow{5}{*}{70.25} & \multirow{5}{*}{0.888} \\
\hline & Establish teaching objectives & 0.873 & & \\
\hline & Select appropriate teaching material & 0.858 & & \\
\hline & Arrange appropriate timeline & 0.832 & & \\
\hline & Prepare teaching material before class sessions & 0.748 & & \\
\hline \multirow{4}{*}{$\begin{array}{l}\text { Instructional } \\
\text { strategy }\end{array}$} & Utilize effective teaching methods & 0.826 & \multirow{4}{*}{76.39} & \multirow{4}{*}{0.895} \\
\hline & Sustain students' attention & 0.889 & & \\
\hline & Inspiring and maintaining students' motivation & 0.907 & & \\
\hline & Utilize various inquiring skills & 0.872 & & \\
\hline \multirow{5}{*}{$\begin{array}{l}\text { Technology } \\
\text { usage }\end{array}$} & Utilize technology to enhance teaching & 0.865 & \multirow{5}{*}{62.72} & \multirow{5}{*}{0.848} \\
\hline & Select appropriate teaching media & 0.891 & & \\
\hline & Product relevant teaching media & 0.762 & & \\
\hline & Employ software relevant to teaching & 0.636 & & \\
\hline & Operate various types of teaching apparatuses & 0.780 & & \\
\hline \multirow{5}{*}{$\begin{array}{l}\text { Classroom } \\
\text { management }\end{array}$} & Promote a democratic environment in class & 0.619 & \multirow{5}{*}{61.25} & \multirow{5}{*}{0.830} \\
\hline & Nurture a pleasant learning environment & 0.702 & & \\
\hline & Maintain a good relationship with students & 0.889 & & \\
\hline & Share personal experiences with students & 0.812 & & \\
\hline & Listen to students & 0.858 & & \\
\hline \multirow{3}{*}{$\begin{array}{l}\text { Interpersonal } \\
\text { Relation }\end{array}$} & Provide assistance to students & 0.899 & \multirow{3}{*}{80.11} & \multirow{3}{*}{0.875} \\
\hline & Co-assess learning results and advise students & 0.884 & & \\
\hline & Provide appropriate assistance to students & 0.903 & & \\
\hline \multirow{5}{*}{$\begin{array}{l}\text { Learning } \\
\text { assessment }\end{array}$} & Utilize a variety of assessment methods & 0.766 & \multirow{5}{*}{65.78} & \multirow{5}{*}{0.861} \\
\hline & Assessment methods fit teaching objectives & 0.860 & & \\
\hline & Provide students the opportunities for exercise & 0.767 & & \\
\hline & Assess students with positive methods & 0.887 & & \\
\hline & Improve teaching from assessment results & 0.768 & & \\
\hline
\end{tabular}

Note: Data were analyzed with principle component analysis 
Factor analysis and internal consistency analysis (Cronbach's $\alpha$ ) were conducted to assess the validity and reliability of this constructed measurement for faculty teaching efficacy in USSH-VNUHCM. Table 1 presents that factor loading values for items designed to measure each factor were consistently large from 0.619 to 0.907 which were greater than the threshold level of 0.5 (Hair, Anderson, Tatham, \& Black, 2006), showing that the twenty-seven items of six factors were all suitable for constructing teaching efficacy. A cumulative explanation from 61.25 to 80.11 percent of this study was greater than the threshold level of 60 percent (Hair et al., 2006). The internal consistency analysis yielded Cronbach's $\alpha$ coefficient from 0.830 to 0.895 in this study higher than the threshold level of 0.6 (Hair et al., 2006) and 0.7 (Nunnally \& Bernstein, 1994), indicating satisfactory reliability for this teaching efficacy measurement. Based on the validation of construct reliability which is concluded that research construct of teaching efficacy is reliable.

The independent variables of this study encompassed two categories (see Table 2). The first was teaching resources including teaching support equipment, internet and computer, technology and software, teaching materials, and classroom space. The second was organizational culture including colleague support, relationship with colleagues, feedback from peers, job autonomy, and efficacy of department meetings.

Table 2. Coding schemes and proportions of the independent variables in this study

\section{University environment factors}

\section{Teaching resources}

Teaching support equipment: measured on a 5-point scale, where $1=$ very dissatisfied, $2=$ dissatisfied, $3=$ sometime, $4=$ satisfied, $5=$ very satisfied $(M=3.21, S D=.83)$

Internet and computer: measured on the same scale as that for teaching support equipment $(M=2.82, S D$ $=.99)$

Technology and software: measured on the same scale as that for teaching support equipment $(M=3.09, S D$ $=.85)$

Teaching materials: measured on the same scale as that for teaching support equipment $(M=3.55, S D=.78)$

Classroom space: measured on the same scale as that for teaching support equipment $(M=3.02, S D=1.02)$

\section{Organizational culture}

Colleague support: measured on a 5-point scale, where $1=$ very dissatisfied, $2=$ dissatisfied, $3=$ sometime, 4

$=$ satisfied, $5=$ very satisfied $(M=3.85, S D=.75)$

Relationship with colleagues: measured on the same scale as that for colleague support $(M=4.04, S D=.69)$

Feedback from peers: measured on the same scale as that for colleague support $(M=3.87, S D=.73)$

Job autonomy: measured on the same scale as that for colleague support $(M=4.18, S D=.72)$

Efficacy of department meetings: measured on the same scale as that for colleague support $(M=3.97, S D=.66)$

\subsection{Data Analyses}

This study employed statistical methods of descriptive analyses and multiple regression analyses to analyze the data. Descriptive analyses of the mean and standard deviations were 
computed to understand the general level of teaching efficacy of faculty members in USSH-VNUHCM. A series of separate stepwise multiple regression analyses were conducted to analyze the effects of university environment factors on each teaching efficacy factors.

\section{Results and Discussion}

\subsection{The Level of Teaching Efficacy of Faculty Members in USSH-VNUHCM}

Table 3 presents the results statistical means $(M)$ and standard deviations $(S D)$ of the level six factors of faculty teaching efficacy in the USSH-VNUHCM. In this study, the survey used a 5 -point scale with responses ranging from $1=$ strongly disagree to $5=$ strongly agree Results indicate that the most faculty members were highly measured with their teaching efficacy ( $M$ $=4.14$ (equivalent of $82.8 \%$ ), $S D=0.52$ ), mirroring the results of the studies by Chang, Lin, and Song (2011). The findings of Chang et al. showed that the average of the total score is 3.32 (equivalent of $83 \%$ ) (measured on a 4-point scale: $1=$ strongly disagree; $4=$ strongly agree) which could be regarded as high as measure on the scale. The research of Mehdinezhad (2012) measured teaching efficacy of faculty members in the following criteria: communication skills, assessment, subject matter, curriculum and instruction, learning environment, and implementing technology which measured on a 5-point scale. His research shows that the respondents rated their teaching efficacy in all factors as good $(M=4.23$ (equivalent of $84.6 \%$ ), $S D=0.65$ ).

The research used different methods, approaches and instruments to measure teaching efficacy for faculty members in higher education, thus, they have different results. There is still much room for university administrators to improve the level of satisfaction of students in the USSH-VNUHCM. As a faculty member explained that these difference results depend on many factors: (1) depending on the him/herself to assessing their teaching efficacy, (2) new requirements require the instructors to change in order to improve the quality of instruction, and (3) teaching experience and quick adoption of the new ones.

Table 3. The results of Means (M) and standard deviations (SD) of the faculty teaching efficacy level in the USSH-VNUHCM

\begin{tabular}{lccc}
\hline Factors & $M$ & $S D$ & Rank \\
\hline Course design & 4.36 & 0.57 & 1 \\
Instructional strategy & 4.14 & 0.66 & 4 \\
Technology usage & 3.96 & 0.59 & 5 \\
Classroom management & 4.27 & 0.53 & 2 \\
Interpersonal relation & 3.89 & 0.77 & 6 \\
Learning assessment & 4.19 & 0.54 & 3 \\
Total & 4.14 & 0.52 & \\
\hline
\end{tabular}

The findings of Table 4 also show that faculty members felt efficacious from the greatest to the least in the following dimensions: course design $(M=4.36, S D=0.57)$, classroom management $(M=4.27, S D=0.53)$, learning assessment $(M=4.19, S D=0.54)$, instructional 
strategy $(M=4.14, S D=0.66)$, technology usage $(M=3.96, S D=0.59)$, and interpersonal relation $(M=3.89, S D=0.77)$, and followed by. The results of this study were supported by researches of Chang, Lin, and Song (2011); Mehdinezhad (2012); and Norton, Richardson, Hartley, Newstead, and Mayes (2005); Paneque and Barbetta (2006). The findings of Chang et al., Norton et al., and Paneque and Barbetta demonstrated that faculty members' score highest on teaching efficacy for course design and least satisfied in instruction strategy. For course design, the finding of this study was the same results with their research. They found that university faculty members are more oriented toward knowledge transmission. However, the results of this study as opposed to their researches for instructional strategy which highly measured in this study.

\subsection{The Effects of University Environment Factors on Faculty Teaching Efficacy}

In Table 4, the findings were stepwise regression analyses to clearly present the effects of variable combinations on the teaching efficacy of the Vietnamese faculty members. The results present coefficients of $\beta$ values, with $\beta>0$ indicating a positive effect and $\beta<0$ indicating a negative effect on the teaching efficacy. The different regression models had different explanation for teaching efficacy across different factors of university environment. The percentages of variance explained by the different combinations of predictors are $38.7 \%$ for course design, $29.7 \%$ for instructional strategy, 32\% for technology usage, $30.8 \%$ for classroom management, $33.8 \%$ for interpersonal relation, and $43.3 \%$ for learning assessment.

For teaching resources, teaching support equipment item had significantly positive effects on all factors of teaching efficacy, except classroom management factor, including course design $(\beta=.341, p<.01)$, instructional strategy $(\beta=.302, p<.05)$, technology usage $(\beta=.266, p$ $<.05)$, interpersonal relation $(\beta=.282, p<.05)$, and learning assessment $(\beta=.270, p<.05)$. In addition, classroom space item had a positive effect on interpersonal relation $(\beta=.224, p$ $<.05)$ and a negative effect on technology usage $(\beta=-.255, p<.05)$. No other teaching resources items showed significant effect on faculty teaching efficacy factors. This finding corresponds to Tschannen-Moran and Woolfolk Hoy (2002) and Chang et al. (2010) indicated that teaching efficacy is weakly related to the teaching support variables (including teaching resources). Teaching support may not be able to enhance teachers' sense of teaching efficacy when they are not clear about their teaching responsibilities or meet the basic needs of instructors. There is as yet no empirical research on the regression between teaching resources and faculty teaching efficacy in Vietnam or even in other parts of the world. The finding of this study therefore, cannot be compared to the findings of others. For the relationship between classroom space and teaching efficacy, one faculty member admitted,

My school encouraged all lecturers to innovate methods to improve the quality of teaching. But... for myself, I encountered a lot of difficulties for my teaching. When I design the content of the course which corresponded with the course objectives and the directions and orientations of the school, however, teaching support did not to meet the basic needs of instructors such as internet, classroom space, materials... And now, the classroom space and the number of students is very difficult to design classroom activities. 
For organizational culture, efficacy of department meetings item had a negative effect on instructional strategy $(\beta=-.297, p<.05)$ and technology usage and $(\beta=-.315, p<.05)$ factors of teaching efficacy. Especially, job autonomy item had significantly positive effects on almost factors of teaching efficacy, including course design $(\beta=.491, p<.001)$, instructional strategy $(\beta=.326, p<.01)$, technology usage $(\beta=.399, p<.01)$, classroom management $(\beta=.304, p<.05)$, interpersonal relation $(\beta=.246, p<.05)$, and learning assessment $(\beta=.333, p<.01)$. For the relationship between job autonomy and teaching efficacy, one faculty member said,

In my opinion, when instructor has autonomy in their work, they will take the initiative and creativity in arranging, allocating time and balancing work... furthermore, they will select the best teaching methods, instruments and strategies for their teaching.

Finally, colleague support item of organizational culture had significantly positive effects on technology usage $(\beta=.334, p<.05)$ and learning assessment $(\beta=.325, p<.05)$ factors of faculty teaching efficacy. The results of this study were supported by researches of McKeachie and Svinicki's (2006) and Chang et al. (2010) demonstrated that support from colleagues is one of the best ways to improve teaching quality and promote teaching effectiveness. In addition, Chang et al. also indicated that colleagues whose have the same department or discipline, they can suggest teaching strategies helpful in dealing with areas that needs improvement. Furthermore, colleague support not only broadens and deepens faculty's teaching predilection to promote teaching efficacy but also enhances their socialization within the universities.

Table 4. Summary of stepwise regression analysis for perceived university environment factors predicting teaching efficacy variables

\begin{tabular}{|c|c|c|c|c|c|c|}
\hline \multirow{2}{*}{ University environment factors } & \multicolumn{6}{|c|}{ Faculty teaching efficacy } \\
\hline & $\mathrm{CD}$ & IS & TU & $\mathrm{CM}$ & IR & LA \\
\hline \multicolumn{7}{|l|}{ 1. Learning resources } \\
\hline Teaching support equipment & $.341 * *$ & $.302 *$ & $.266 *$ & .066 & $.282 *$ & $.270 *$ \\
\hline Internet and computer & .083 & .024 & -.152 & .087 & .000 & .015 \\
\hline Technology and software & .147 & -.014 & .201 & -.128 & -.061 & .016 \\
\hline Teaching materials & -.221 & .148 & -.005 & .071 & -.092 & -.075 \\
\hline Classroom space & -.204 & -.133 & $-.255^{*}$ & .116 & $.224 *$ & -.009 \\
\hline \multicolumn{7}{|l|}{ 2. Organizational culture } \\
\hline Colleague support & .106 & .121 & $.334 \%$ & .049 & .208 & $.325 *$ \\
\hline Relationship with colleagues &.-041 & -.170 & .005 & .097 & -.165 & -.197 \\
\hline Feedback from peers & .130 & .246 & .017 & .240 & .238 & .230 \\
\hline Job autonomy & $.491 * * *$ & $.326 * *$ & $.399 * *$ & $.304 *$ & $.246 *$ & $.333 * *$ \\
\hline Efficacy of department meetings & -.128 & $-.297 *$ & $-.315 *$ & -.207 & -.097 & -.057 \\
\hline $\mathrm{R}$ & .622 & .545 & .565 & .555 & .581 & .658 \\
\hline $\mathrm{R}^{2}$ & .387 & .297 & .320 & .308 & .338 & .433 \\
\hline
\end{tabular}

Note. ${ }^{*} p<.05, * * p<.01, * * * p<.001$. CD: Course design, IS: Instructional strategy, TU: Technology usage, CM: Classroom management, IR: Interpersonal relation, LA: Learning assessment. 
Unfortunately, the studies of the relationship between faculty teaching efficacy and university environment factors are very few in order to discuss with the results of this study. Further research about the relationship between faculty teaching efficacy and university environment factors will contribute to fill in the literature gap.

\section{Conclusion}

Teaching efficacy of faculty members in higher education have a positive influence on teaching performance and students' learning achievement. Faculty members with a high sense of efficacy tend to exhibit greater levels of planning, organization, enthusiasm, spend more time teaching in areas, more open to new ideas, more committed to teaching, and more willing to experiment with new methods.

The purpose of this study was to investigate university faculty's perceptions of teaching efficacy in Vietnam and the relationship of perceived university environment factors to faculty' teaching efficacy was examined. The results showed that the most faculty members were highly measured with their teaching efficacy; however, there is still much room for university administrators to improve the teaching efficacy level of faculty members in Vietnamese higher education. This study has also demonstrated that university environment factors had significant effect on faculty teaching efficacy in Vietnam. The difference university environment factors had different effects for faculty teaching efficacy across different factors of faculty teaching efficacy. Hence, when university managers and policy makers want to improve a universal intervention to enhance faculty teaching efficacy, they should be notably concerned about both these factors.

The primary limitation is that only USSH-VNUHCM faculty members were sampled in this study, and thus, the results and implications should be applied with caution to faculty members from different levels of higher education institutes or academic disciplines. Further research should collect faculty member samples from various higher education levels and disciplines. It would be also interesting to examine the interaction between teaching resources and organizational culture factors on their teaching efficacy. The link between faculty teaching efficacy and other factors of university environment (e.g., administrator support, job satisfaction, teaching support, leadership style...) could be confirmed by direct observation in future studies.

This study suggests that administrators should be aware what their faculty really need for teaching while providing teaching support. It is hoped that the barrier to the teaching efficacy of faculty members are found in this study may be useful for university management to develop work environment and culture that would allow higher levels of faculty teaching efficacy and can contribute to a great extent to improve the level of faculty members in Vietnamese higher education.

\section{Acknowledgment}

I would like to acknowledge my sincere gratitude to anonymous, kindest support and help, valuable advice, synthesized comments on revision, and detailed editing throughout. 


\section{References}

Allinder, R. M. (1994). The relationship between efficacy and the instructional practices of special education teachers and consultants. Teacher Education and Special Education, 17(2), 86-95. http://dx.doi.org/10.1177/088840649401700203

Ashton, P. T., \& Webb, R. B. (1986). Making a difference: Teachers' sense of efficacy and student achievement. White Plains, NY: Longman.

Bandura, A. (1986). Social foundations of thought and action: A social cognitive theory. Englewood Cliffs, NJ: Prentice-Hall.

Bandura, A. (1997). Self-efficacy: The exercise of control. New York: Freeman.

Brouwers, A., \& Tomic, W. (2003). A test of the factorial validity of the Teacher Efficacy Scale. Research in Education, 69(1), 67-79. https://doi.org/10.7227/RIE.69.6

Brown, G. (1993). Effective teaching. In R. Ellis (Ed.) Quality assurance for university teaching (pp. 211-232). Bristol, PA: Open University Press.

Carara, G., Barbaranelli, C., Steca, P., \& Malone, P. (2006). Teachers' self-efficacy beliefs as determinants of job satisfaction and students' academic achievement: a study at the school level. Journal of School Psychology, 44(1), 473-90. http://dx.doi.org/10.1016/j.jsp.2006.09.001

Chang, T. S., McKeachie, W., \& Lin, Y. G. (2010). Faculty perceptions of teaching support and teaching efficacy in Taiwan. Higher Education, 59, 207-220. http://dx.doi.org/10.1007/s10734-009-9243-8

Chang, T. S; Lin, H. H; \& Song, M. M. (2011). University faculty members' perceptions of their teaching efficacy. Innovations in Education and Teaching International, 48(1), 49-60. http://dx.doi.org/10.1080/14703297.2010.543770.

Cook, P. (1998). The influence of organizational characteristics of faculty teaching self-efficacy. Unpublished doctoral dissertation. Vanderbilt University, Nashville, Tennessee.

Darling-Hammond, L., Chung, R., \& Frelow, F. (2002). Variation in teacher preparation: How well do different pathways prepare teachers to teach? Journal of Teacher Education, 53(4), 286-302. http://dx.doi.org/10.1177/0022487102053004002

Dillman, D. A. (2000). Mail and internet surveys: The tailored design method. New York: John Wiley and Son.

Esterly, E. J. (2003). A multi-method exploration of the mathematics teaching efficacy and epistemological beliefs of elementary preservice and novice teachers. Unpublished Ph.D Dissertation, Ohio State University, Ohio.

Giallo, R., \& Little, E. (2003). Classroom behavior problems: the relationship between preparedness, classroom experiences, and self-efficacy in graduate and student teachers. Australian Journal of Educational \& Developmental Psychology, 3(1), 21-34. 
Gibson, S. \& Dembo, M., (1984). Teacher efficacy: A construct validation. Journal of Educational Psychology, 76(4), 569-582. DOI.org/10.1037/0022-0663.76.4.569

Gkolia, A., Belias, D., \& Koustelios, A. (2014). Teacher's job satisfaction and self-efficacy: A review. European Scientific Journal, 10(22), 321-342.

Goddard, R. D., Hoy, W. K., \& Woolfolk Hoy, W. (2000). Collective teacher efficacy: Its meaning measure, and impact on student achievement. American Educational Research Journal, 37(2), 479-507. http://dx.doi.org/10.3102/00028312037002479

Gonyea, R. M. (2005). Self-reported data in institutional research: Review and recommendations. In P. D. Umbach (Ed.), Servey research: Emerging issues (pp. 73-89). San Francisco, CA: Jossey-Bass.

Gow, L., \& Kember, D. (1993). Conceptions of teaching and their relationship to student learning. The British Journal of Educational Psychology, 63, 20-33. http://dx.doi.org/10.1111/j.2044-8279.1993.tb01039.x

Hair, J. F., Anderson, R. E., Tatham, R. L., \& Black, W. C. (2006). Multivariate data analysis. New Jersey: Prentice Hall.

Henson, K. (2001). Relationships between pre-service teachers' self-efficacy, task analysis, and classroom management beliefs. Paper presented at the Annual Meeting of the Southwest Educational Research Association, New Orleans

Kim, E. (2009). Beyond language barriers: Teaching self-efficacy among East Asian international teaching assistants. International Journal of Teaching and Learning in Higher Education, 21(2), 171-180.

Lin, H. L., \& Gorrell, J. (2001). Exploratory analysis of pre-service teacher efficacy in Taiwan. Teaching and Teacher Education, 17(5), 623-635. http://dx.doi.org/10.1016/S0742-051X(01)00018-X

Malaney, G. D. (2002). You still need high response rates with web-based surveys. Student Affairs On-Line, 3(1).

McKeachie, W. J., \& Svinicki, M. (2006). McKeachie's teaching tips: Strategies, research, and theory for college and university teachers (12th ed.). Boston: Houghton Mifflin.

Mehdinezhad, V. (2012). Faculty members' understanding of teaching efficacy criteria. Education Inquiry, 3(1), 49-69. http://dx.doi.org/10.3402/edui.v3i1.22013

Norton, L., Richardson, J., Hartley, J., Newstead, S., \& Mayes, J. (2005). Teachers' beliefs and intentions concerning teaching in higher education. Higher Education, 50(4), 537-571. http://dx.doi.org/10.1007/s10734-004-6363-z

Nolen, S., Ward, C., Horn, I., Campbel, S., Mahna, K., \& Childers, S. (2007). Motivation to learn during student teaching. Paper presented at the annual meeting of the American Educational Research Association, Chicago. 
Nunnally, J. C., \& Bernstein, I. H. (1994). Psychometric theory (2nd ed.). New York, NY: McGraw-Hill.

Paneque, O. M., \& Barbetta, P. M. (2006). A study of teacher efficacy of special education teachers of English language learners with disabilities. Bilingual Research Journal: The Journal of the National Association for Bilingual Education, 30(1), 171-193. http://dx.doi.org/10.1080/15235882.2006.10162871

Ross, J. A. (1994). Beliefs that make a difference: The origins and impacts of teacher efficacy. Paper presented at the annual meeting of the Canadian Association for Curriculum Studies.

Ross, J., \& Bruce, C. (2007). Professional development effects on teacher efficacy: Results of randomized field trial. The Journal of Educational Research, 101(1), 50-60. http://dx.doi.org/10.3200/JOER.101.1.50-60

Tschannen-Moran, M., \& Woolfolk Hoy, A. (2001). Teacher efficacy: Capturing an elusive construct. Teaching and Teacher Education, 17, 783-805. http://dx.doi.org/10.1016/S0742-051X(01)00036-1.

Tschannen-Moran, M., \& Woolfolk Hoy, A. (2002). The influence of resources and support on teachers' efficacy beliefs. Paper presented at the annual meeting of the American Educational Research Association, New Orleans, LA.

Tschannen-Moran, M., Woolfolk Hoy, A., \& Hoy, W. K. (1998). Teacher efficacy: Its meaning and measure. Review of Education Research, 68(2), 202-248. http://dx.doi.org/10.3102/00346543068002202

Tournaki, N., \& Podell, D. M. (2005). The impact of student characteristics and teacher efficacy on teachers' predictions of student success. Teaching and Teacher Education, 21, 299-314. https://doi.org/10.1016/j.tate.2005.01.003

Usher, E. \& Pajares, F. (2006). Inviting confidence in school: invitations as a critical source of the academic self-efficacy beliefs of entering middle school students. Emory University Journal of Invitational Theory and Practice, 12, 7-16.

Woolfolk Hoy, A. (2004). Self-efficacy in college teaching. Essays on Teaching Excellence: Toward the Best in the Academy, 15(7), 8-11. Fort Collins, CO: The POD Network.

Woolfolk-Hoy, A., \& Davis, H. (2006). Teacher self-efficacy and its influence on the achievement of adolescents. In F. Pajares \& T. Urdan (ed.), Self-efficacy beliefs of adolescents, (pp. 117-13)8. Charlotte, NC: Information Age.

\section{Copyright Disclaimer}

Copyright reserved by the authors.

This article is an open-access article distributed under the terms and conditions of the Creative Commons Attribution license (http://creativecommons.org/licenses/by/3.0/). 